\title{
Incidentaloma suprarrenal. A propósito de un caso
}

M. Repiso Moreno, Ma - S. Casis Navajas*, Māj J Elizondo Pernaut** Médico de Familia. *Servicio de M edicina Interna. **Diplomada en Enfermería. Complejo Hospitalario San Millán-San Pedro. Logroño.

\section{RESUMEN}

El hallazgo de masas suprarrenales descubiertas de forma accidental ante la utilización de técnicas de imagen abdominales para el estudio de otras pa tologías es un problema cada vez más frecuente.

Se presenta el caso de un varón de 55 años al que se le descubrió una masa en glándula suprarrenal derecha de forma accidental.

Su aparición requiere un estudio de funcionalidad hormonal y técnicas de imagen para determinar su naturaleza y tamaño.

La actitud a seguir es el control evolutivo, dado que su tamaño es menor de $6 \mathrm{~cm}$ y tras descartar hi persecreción hormonal patológica e imágenes su gestivas de malignidad.

Palabras clave: Masa suprarrenal. Tamaño. Hi perfunción hormonal.

\section{INTRODUCCIÓN}

Con el aumento en la utilización de pruebas diagnósticas de imagen en medicina es cada vez más frecuente la descripción de masas suprarrenales descubiertas de forma casual, los denominados incidentalomas.

Se calcula que por encima de los 40 años aproximadamente el $0,5-1 \%$ de la población podría presentarlos ${ }^{1}$.

\section{CASO CLÍNICO}

Varón de 55 años que, a raíz de un traumatismo por accidente laboral, se le realiza una ecografía abdominal en la que se objetiva una masa en glándula suprarrenal derecha.

\section{Adrenal incidentaloma. A case review}

\section{ABSTRACT}

Adrenal masses discovered in the course of abdo minal imaging studies performed because other rea sons are a common problem.

We report a case of a 55 years old man with a right adrenal masse incidentally discovered.

This study requires the exclusion of hypersecre ting lesions and imaging studies to determine its nature and size.

In our case the management recommended is the morpho-functional follow-up.

Key words: Adrenall masse. Size. Hormonal hy persecretion.
Entre sus antecedentes personales, destaca una hipertensión arterial en tratamiento farmacológico con diurético y la ingesta de aproximadamente 60 gramos de etanol al día.

La exploración física es normal y la tensión arterial es de 140/70 $\mathrm{mmHg}$.

Exploraciones complementarias (entre paréntesis los valores normales):

-Analítica de sangre: hemograma, bioquímica (sodio $141 \mathrm{mmol} / 1$, potasio $3,9 \mathrm{mEq} / \mathrm{l}$ ) y coagulación compatibles con la normalidad.

-Analítica de orina: sedimento compatible con la normalidad.

-Orina de 24 horas: creatinina 2,1 g (1-2), aclaramiento de creatinina $160 \mathrm{ml} / \mathrm{min}$ (70-120), sodio $183 \mathrm{mmol}$ (30-300), potasio $64 \mathrm{mmol}$ (35-80), proteínas $62 \mathrm{mg}(0-200)$. 
—El electrocardiograma y la radiología de tórax y abdomen no son patológicos.

- La ecografía abdominal muestra una lesión nodular hipoecoica en área de glándula suprarrenal derecha.

- Se realiza una tomografía axial computarizada (TAC) abdominal en la que se aprecia una glándula suprarrenal derecha agrandada de volumen, de morfología más o menos ovoidea de unos 23 x $9 \mathrm{~mm}$, bien delimitada, que no capta contraste de forma significativa, sin otros hallazgos patológicos en suprarrenal izquierda ni en resto de cavidad abdominal.

-Estudio hormonal: aldosterona en suero por radioinmunoensayo ( RIA): 140 pg/ml (100-160).

Aldosterona en suero (test de furosemida y deambulación): 149 pg/ml (100-160).

Renina plasmática (RIA): 0,3 ng/ml/h (0,2-2,3).

Renina plasmática (test de furosemida y deambulación): 0,4 ng/ml/h (0,2-2,3).

ACTH plasmática (RIA): basal $20 \mathrm{pg} / \mathrm{ml}(<52)$.

Catecolaminas libres en orina: noradrenalina 36 $\mu \mathrm{g} / 24 \mathrm{~h}(<76)$, adrenalina $<6 \mu \mathrm{g} / 24 \mathrm{~h}(<18)$, dopamina $350 \mu \mathrm{g} / 24 \mathrm{~h}(<390)$.

Metanefrinas fraccionadas en orina: metanefrina $41 \mu \mathrm{g} / 24 \mathrm{~h}$ (52-341), normetanefrina $162 \mu \mathrm{g} / 24 \mathrm{~h}$ (88-444).

DHEA-sulfato: $1,1 \mu \mathrm{g} / \mathrm{ml}(0,8-5,6)$.

Test de Nuggent (supresión con $1 \mathrm{mg}$ de dexametasona la noche anterior): a la mañana siguiente cortisol plasmático $<1 \mu \mathrm{g} / \mathrm{dl}$ (suprime).

Diagnóstico

Incidentaloma.

Se trata de un nódulo suprarrenal derecho de menos de $3 \mathrm{~cm}$ en el momento actual normofuncionante. La actitud a seguir sería su control evolutivo.

\section{DISCUSIÓN}

Los incidentalomas son masas suprarrenales descubiertas de forma accidental.

Se calcula que entre el 0,35 al 4,36\% de las exploraciones abdominales realizadas mediante ecografía, TAC o resonancia magnética demuestran una lesión suprarrenal previamente no sospechada ${ }^{1}$.

Etiológicamente la mayoría (>90\%) son benignos y no secretores (adenomas, quistes, lipomas, miolipomas, etc.) y aproximadamente un $4 \%$ son malignos (carcinomas primarios o metastásicos, neuroblastomas) ${ }^{2}$.

Hay dos aspectos claves en el manejo de estas masas, por una parte determinar su naturaleza o, por lo menos, descartar malignidad, y por otra parte descartar producción hormonal patológica. No obstante, no hay unos criterios claros sobre el tipo de estudio diagnóstico a realizar.

En el estudio de la función hormonal tendremos en cuenta los siguientes aspectos ${ }^{3,4}$ :

- Para valorar la presencia de hipercortisolismo y, teniendo en cuenta la posibilidad de un tumor productor de cortisol sin evidencia de síndrome de $\mathrm{Cu}$ shing, lo más útil sería el test de Nugent (supresión con $1 \mathrm{mg}$ de dexametasona).
- Para valorar la actividad mineralocorticoide hay que determinar inicialmente el sodio y el potasio en orina y, en aquellos casos en que haya hipertensión arterial o alteraciones hidroelectrolíticas se completará el estudio con la determinación de la aldosterona y actividad de renina plasmáticas.

El estudio de la actividad androgénica es discutido dada la escasa frecuencia de este tipo de tumores en ausencia de síntomas, pero la dehidroepiandrosterona sulfato (DHEA-S) es un buen marcador de la producción suprarrenal de andrógenos.

La probabilidad de que en ausencia de hipertensión arterial una masa suprarrenal no sea un feocromocitoma es del 96,5\%, no obstante dada la gravedad del cuadro se recomienda la determinación de catecolaminas urinarias en 24 horas ${ }^{3}$.

Para el estudio de su naturaleza las pruebas de imagen como la TAC o la RM son muy útiles para diferenciar una lesión benigna de una maligna. No obstante, en pacientes con neoplasias extraadrenales y riesgo de metástasis suprarrenales y en el diagnóstico diferencial de un quiste, es útil la punción citológica con aguja fina (PAAF) guiada por ecografía o TAC, aunque desgraciadamente no siempre es posible descartar malignidad por este método ante una masa sólida. Por todo ello el tamaño adquiere una importancia fundamental, ya que la probabilidad de encontrar un carcinoma en una masa suprarrenal de tamaño menor de $2 \mathrm{~cm}$ es de $1 / 4.000^{3}$.

La gammagrafía suprarrenal con colesterol marcado es una técnica que puede tener utilidad en el estudio de esta patología y las lesiones que muestran menor captación del isótopo tienen un mayor riesgo de malignidad.

En cuanto al manejo de este tipo de masas también hay aspectos controvertidos.

Está fuera de toda duda que los tumores funcionantes, independientemente de su tamaño, requieren tratamiento quirúrgico.

En el caso de masas no funcionantes la decisión se toma en función del tamaño del tumor. Dado que la suprarrenalectomía no es una cirugía exenta de riesgos, la mayoría de los autores recomiendan el tratamiento quirúrgico en las masas sólidas mayores de 6 $\mathrm{cm}$, aunque otros ponen el límite en $3 \mathrm{~cm}^{5,6}$. En los menores de $6 \mathrm{~cm}$ la actitud más aceptada es su seguimiento evolutivo.

En estudios de seguimiento realizados en incidentalomas menores de $6 \mathrm{~cm}$, parece que el tamaño de la masa mayor de $3 \mathrm{~cm}$ en el momento del diagnóstico es un factor de riesgo para el desarrollo de hiperfunción adrenal? ${ }^{7}$.

CORRESPONDENCIA:

Manuel Repiso Moreno

Avda. Eulza $77-1^{\circ} \mathrm{D}$

31010 Barañaín

Navarra 


\section{Bibliografía}

1. Prinz R, Brooks M, Churchill R, Graner J, Lawrence A, Paloyan A. Incidental asyntomatic adrenal masses detected by computed tomographic scanning. Is operation required? JAMA 1982; 163 : 701-4.

2. Rodríguez A, Cánovas G, Díaz I. Enfermedades de las glándulas suprarrenales. En: Manual de diagnóstico y terapéutica médica. Madrid: Hospital Universitario 12 de Octubre (4ª ed.), 1998; 64151 .

3. Federico J, Soriguer Escofet. Masa suprarrenal descubierta casualmente. Manual de pruebas diagnósticas en Endocrinología. $1^{a}$ ed. Madrid 1994; 87-100.

4. Leal- Cerro A, Ayala C, Venegas E. Protocolo diagnóstico- terapéutico ante un incidentaloma. Medicine 1997; 7 (46); 2051- 5 .

5. Vilardell E. Enfermedades de las glándulas suprarrenales. En: Farreras - Rozman. Medicina Interna. 13 ${ }^{\mathrm{a}}$ ed. Barcelona: Doyma, 1995; 2: 2138

6. Bencsik Z, Szabolcs I, Góth M, Vörös A, Kaszás I, Gönczi J, et al. Incidentally detected adrenal tumours (incidentalomas): histological heterogeneity and differentiated therapeutic approach. J Intern Med 1995; 237: 585-9.

7. Barzon L, Scaroni C, Sonino N, Fallo F, Paoletta A, Boscaro M. Risk factors and long-term follow-up of adrenal incidentalomas. J Clin Endocrinol Metab 1999; 84 -2: 520-6. 